\title{
Surveys as Cultural Artefacts: Applying the International Self-Report Survey on Juvenile Delinquency to Latin American Adolescents
}

\section{Juan Antonio Rodríguez, Universidad de Los Andes, Venezuela Neelie Pérez-Santiago, Universidad Central de Venezuela \\ Christopher Birkbeck, University of Salford, UK}

Introduction
The International Self-Report Survey of Delinquency: A Brief Biography
Cultures in Contrast
Obvious Differences.
Going Deeper: Normative Ambiguity
Conclusion...
References .

\footnotetext{
ABSTRACT

Survey instruments are often watermarked with the language, thought patterns, experience and expectations of their designers' cultural world. This creates some evident challenges when using surveys in international research projects (e.g., in finding equivalent terms in translation), but also some less evident ones deriving from potentially hidden local variations in social experience, values and cognition. Using examples from the International Self-Report Survey on Juvenile Delinquency, this article identifies several potential challenges to measurement that arise when an instrument designed with the youth of industrialised democracies in mind is presented to adolescents in a Latin American country (Venezuela). Some strategies for addressing these challenges are outlined.
} 


\section{Introduction}

How well do survey instruments travel? This question nicely captures the challenges identified by many researchers interested in international projects (e.g., Berry et al., 2002; Greenfield, 1997). Put simply, will instruments originating in one culture have the same level of validity and reliability when used in other cultures? Or will 'imported' instruments interact with the cultural characteristics of local respondents to generate changes to measurement which confound the comparisons between survey sites? For example, does the embarrassment reportedly felt by women in Uganda (see, Ssamula, 1995) and probably in many other places - when asked about incidents of sexual victimisation lead to comparative under-reporting in that country? Or would items concerning mental maps of crime be affected by the fact that Colombians apparently do not orient themselves in terms of cardinal directions (Ardila, 2007)? These sorts of question call for assessments of the extent to which survey instruments reflect their originators' cultural world; whether demonstrably idiosyncratic content affects measurement; and how any resulting biases can be overcome.

Such matters can only be resolved by sustained inquiry. Thus, while the notion of travel invokes an image of the manufacture, transport and application of survey instruments, patterns of international usage are evidently more complicated than this. Instruments that 'travel' represent the cross-cultural model of survey diffusion which, in its pure form, is exemplified by a research group in one culture designing an instrument and then using it in other cultures. The alternative model is multicultural, in which researchers from several cultures come together to design a common instrument that they use at each site. Indeed, these two models could be placed at the opposite ends of a scale and specific research initiatives located along it. But, while the cross-cultural model is more likely than the multicultural model to pose questions about the validity and reliability of the research instrument, a detailed assessment of items in terms of their cultural uniqueness or generality is necessary in all international survey projects. 
Similarly, while assessments of survey items' cultural specificity can be made with varying degrees of certainty, the effects of that specificity (if any) on the data generated requires systematic investigation. Social scientists have devoted considerable efforts to studying the interaction between instrument design and resulting responses, well exemplified in criminology by the extensive methodological work on surveys that measure offending or victimization (Junger-Tas and HaenMarshall, 1999; Lynch and Addington, 2011; Thornberry and Krohn, 2000). However, the exploration of these effects in the international context has been absent from criminology and is only beginning to be addressed in other fields, such as development studies and health (e.g., Beaman and Dillon, 2012; Das, Hammer and Sánchez-Paramo, 2012).

In this paper, we use the application of the International Self-Report Delinquency Study (ISRD) in Venezuela as a case study to explore the particularities of an international survey instrument and assess their implications for the validity and reliability of measurement. Our argument will be that the ISRD instrument is quite strongly imprinted with the culture that spawned it, a culture that reflects the highly industrialised societies of Northern Europe, the U.S. and Canada. Although an urbanised middle-income and oil-rich country, in many studies of the world's major cultural types Venezuela is often classed with less industrialised societies - for example, as a 'collectivist' rather than 'individualist' (Hofstede, [1980] 2001) or 'high-context' rather than 'low-context' (Hall, 1976) culture. The particularities of the ISRD survey instrument are identified through an exploration of differences between the experiential and cognitive world conveyed by its items and the experiential and cognitive world likely to be inhabited by many Venezuelan adolescents. Some of these differences are relatively easy to detect and substantiate, originating in varying organisational arrangements for activities and institutions. Others are fairly easy to detect but more difficult to substantiate, for example those arising from the normative ambiguity that surrounds specific behaviours which puts their validity as measures of delinquency in doubt. Still others are difficult both to detect and substantiate, requiring a keen eye for social arrangements and cognitive 
frameworks and extensive research to document them. Drawing on a variety of sources and approaches, we suggest some Venezuelan particularities at each of these levels and speculate on the possible impact of these particularities on the validity and reliability of the data collected with the ISRD instrument. At each level we briefly propose a strategy for dealing with measurement issues.

\section{The International Self-Report Survey of Delinquency: A Brief Biography}

Like the International Crime Victimisation Survey (ICVS) before it, ${ }^{1}$ the ISRD project was launched from the Netherlands (Junger-Tas, 2010). The initial methodological experiments in surveys of self-reported delinquency had been conducted in the United States and had led to the conclusion, later summarised by Thornberry and Krohn (2000:33), that 'self-report [offending] data appear acceptably valid and reliable for most research purposes.' Indeed, self-report surveying of delinquency had been institutionalised in the U.S. National Youth Survey (NYS) since the mid-1970s (Elliott and Huizinga, 1989). This experience provided some of the intellectual and methodological antecedents to the ISRD (e.g., Klein, 1989) which was initiated by the Dutch Research and Documentation Centre in 1990 (Aebi, 2009).

Like the NYS, the first ISRD project (ISRD-1, carried out between 1991 and 1992) focused on youths (12-18) and sought out respondents in their household or school. Thirteen countries participated in the study, mainly from Europe but also including the United States. The second ISRD project (ISRD-2) conserved many of the characteristics of the first project while also instituting some changes (Junger-Tas et al., 2010). It narrowed the target age group being studied to students attending $7^{\text {th }}$ to $9^{\text {th }}$ grade (roughly 12-16 years old depending on the educational system of each country); mainly involved city samples in each country; and used exclusively school-based samples. Project leadership was provided by an international group of scholars based in Western Europe and North America, who had principal

\footnotetext{
${ }^{1}$ See van Dijk (in this issue).
} 
responsibility for deciding on the sampling strategy and design of the instrument. Other countries were invited to participate and a total of 31 undertook data collection between 2005 and 2007. Of these, 25 were located in Europe and six in the Americas. The latter included Canada and the USA but also two Caribbean island nations (Aruba, Netherlands Antilles) and two South American countries (Surinam, Venezuela).

The third ISRD project (ISRD-3, 2012-14) covered a similar number, and spread, of countries as the second sweep (again, including Venezuela). It retained the same target age group, school-based sampling, and a similar city-based sampling strategy as ISRD-2, along with many of the latter's survey items. In line with the project coordinators' ambitions to use the ISRD project to test current criminological theories, questions from previous sweeps on self-control, family, school and neighbourhood bonding were accompanied in ISRD-3 by questions relating to situational action theory (Wikström, 2009), institutional anomie (Messner and Rosenfeld, 2007) and procedural justice (Tyler, 2006).

In terms of the two models of international survey work identified previously (cross-cultural, multicultural), the ISRD is an intermediate case. Its roots in U.S. criminology have undoubtedly exercised a strong influence on the choice of variables to be measured in the survey and on the cognitive framework employed for eliciting information about the prevalence and incidence of the behaviours of interest. The European sponsors and associated participants in the ISRD have engaged in fairly extensive discussions about the instrument's design, particularly regarding the items for measuring delinquency (Junger-Tas et al., 2010:2; Junger-Tas, Haen-Marshall and Ribeaud, 2003:4). However, the extent to which varied social arrangements, expectations and mindsets across the countries participating in the survey could affect the validity and reliability of the instrument has not been fully considered, even as the project has extended to Eastern Europe and Russia and to the Caribbean and South America. This is undoubtedly due to the considerable effort required to develop comparable samples (Haen-Marshall, 
2010), and the obvious requirement to use a common, standardised, instrument. In meeting this latter requirement, attention has focused on translation rather than item design. In the following sections, we discuss some of the potentially ethnocentric characteristics of the ISRD-3 survey instrument by offering contrasting examples - some easily detected and substantiated, others less so - from Venezuela.

\section{Cultures in Contrast}

As shown in Table 1, the ISRD-3 instrument consists of eleven modules containing 73 main questions. Many of the latter include itemized repetitions of the main question; for example, Question 7.1 on offending behaviour has 15 separate sub-sets of questions, each referring to a specific kind of offence. As is to be expected, many of the items in the instrument do not raise concerns about cultural equivalence - at least from the vantage point of urban Venezuela. ${ }^{2}$ For example, asking adolescents from Caracas to indicate their age in years, whether they have lost a parent through death, and how frequently they do homework, looks to be no different to asking the same thing of adolescents in most other big cities around the world. Our analysis of the cultural particularities in the ISRD instrument focuses on selected questions or sub-items, proceeding from examples that are fairly obvious, easily substantiated and easy to resolve, to cases which are suggestive, less easily substantiated and somewhat more difficult to resolve.

\begin{tabular}{|l|}
\hline \multicolumn{1}{|c|}{ Table 1: ISRD-3 - Overview of the Instrument } \\
\hline PART 1 (core) \\
Module 1 Demographic background (questions 1.1--1.15) \\
Module 2 Family (questions 2.1-2.4) \\
Module 3 School (questions 3.1-3.7) \\
\hline
\end{tabular}

\footnotetext{
${ }^{2}$ Greenfield (1997) cites examples from pre-industrial cultures which indicate that even some of the basic and taken-for-granted assumptions about cognition and meaning in Western societies, such as modes of classifying objects, are culturally variant and require careful thought in survey and test design. Because we did not include pre-industrial groups (such as the Warao, Wayúu, or Yanomami) in our Venezuelan sample, we do not explore cultural differences to this level.
} 
Module 4 Victimization (question 4.1)

Module 5 Leisure and peers (questions $5.1-5.10$ )

Module 6 Attitudes and values (questions $6.1-6.7$ )

Module 7 Offending (question 7.1-7.2)

PART 2 (sweep-specific)

Module 8 Substance use (questions $8.1-8.6$ )

Module 9 Norm transmission strength (questions 9.1 -9.4)

Module 10 Procedural justice questions (questions $10.1-10.8$ )

PART 3 (optional or country-specific)

Module 11 Gang $(11.1-11.8)$

Final question (Module 98, not numbered: response integrity)

\section{Obvious Differences}

When referring to objects, activities and institutions, survey items may incorporate the typical experiences of their designers. For example, one of the behaviours itemized in the ISRD-3 delinquency inventory is stealing a bicycle. This presumably reflects the prevalence of bicycles (and their theft) in Western Europe, especially The Netherlands. By contrast, despite a growing minority of sports enthusiasts, Venezuela is a country where cycling is almost entirely absent from urban streets and roads, perhaps partly because of the perceived risks of riding in anarchical traffic and partly because of the tropical climate. Thus, asking Venezuela adolescents about bicycle theft is probably of little relevance when attempting to measure the quantity and variety of their delinquent behaviour. Similarly, another item asks respondents if they have taken part in 'a group fight in a football stadium, on the street or other public place.' Here, the prominent mention of football stadia evokes not just the world of European soccer but its potential significance for youth violence. As a sporting country, Venezuela is more Caribbean than Latin American, with a stronger development of baseball than football. Although there has been some violence at soccer matches, the majority of Venezuelans are more likely to have 
attended a baseball game, if they have been to a sports event at all - for rates of attendance at sporting events may be lower than in Europe or Anglo America.

Finally, a subsequent question asks respondents if they have ever had contact with the 'police' concerning the types of offending listed earlier in the survey. Additionally, Module 10 has eight questions concerning perceptions of the 'police.' The difficulty here concerns who a Venezuelan adolescent might think of when asked about the 'police.' This is because, as in most Latin American countries, there are a number of different agencies that engage in police work, but not all of them have the word 'police' in their title. In Caracas, for example, adolescents may encounter officers attached to the National Police (Policía Nacional Bolivariana), created in 2009 through the amalgamation of state, municipal and traffic police. However, they will also see 'national guards' from the Guardia Nacional Bolivariana, a hybrid military and civilian corps assigned to street patrol and public order, along with 'detectives,' 'functionaries' or 'agents' from the 'scientific police' (Cuerpo de Investigaciones Cientificas, Penales y Criminalísticas) who investigate crime and undertake some patrol activities. So, when answering the questions in the ISRD-3 instrument, would an adolescent think of those who are called 'police' or those who engage in police work? And might perceptions and experiences vary quite markedly for different agencies? ${ }^{3}$

Fortunately, the superficial nature of this type of problem, deriving as it does from different arrangements regarding activities and institutions, suggests relatively simple solutions. Thus, the varied importance of bicycles and soccer across different cultures points to the need to frame questions in terms of more generalised referents. For example, respondents could be asked about the theft of 'things,' with some generalized examples mentioned (e.g., phones, wallets, or money) or several more particular examples included (e.g., bicycles [Europe], and backpacks [Latin America]). In relation to group fights, football stadia could be changed to 'sports events or concerts' and relegated to the end of

\footnotetext{
${ }^{3}$ The potential confusion is not unique to Venezuela, being shared with other Latin American countries and also some European ones (e.g., Spain, Italy).
} 
the question. ${ }^{4}$ And for questions on the police, the relevant agencies would need to be briefly indicated in each country.

\section{Going Deeper: Normative Ambiguity}

As commentators on the self-reported assessment of delinquency have pointed out, the operationalization of youth offending is not without problem (Elliott and Huizinga, 1989; Junger-Tas and Haen-Marshall, 1999; Thornberry and Krohn, 2000). Within industrialised countries, discussion has focused mainly on the validity of status offences and trivial delinquent behaviour as measures of offending, on the number and range of offences included in surveys, and on the way in which the incidence of offending is counted. International projects raise the additional matter of varied normative and legal perspectives on behaviour: what is a problematic or delinquent conduct in one country may not be so in another. While the ISRD coordination team has done much to develop a set of items that are common to all participating countries, the inclusion of Venezuela in ISRD-2 and ISRD-3 highlights the need for continued discussion about the cultural equivalence of some of the questions.

For example, one item asks respondents if they have ever 'painted on a wall, train, subway or bus (graffiti).' We note, in passing, that trains are another example of a superficial difference: the single suburban train line in operation in Caracas since 2006 contrasts with the dense and longstanding networks of trains in Western Europe and some other parts of the world. But more problematic is the reference to graffiti. Although the term is known in Venezuela and used to evaluate street painting as either art or vandalism (e.g., El Universal, 2011), there is also a rich variety of street 'messaging,' including political protest and propaganda, moral slogans, gang-style tagging and even declarations of love (cf. Alonso, 1998). Numerous and highly varied groups and individuals fill many walls in public spaces, which often include the boundary walls of many private properties. Painting on walls might

\footnotetext{
${ }^{4}$ For a similar example relating to the varying national prominence of particular sports, see Banville, Desrosiers and Genet-Volet (2000:375)
} 
seem unsightly to those who worry about urban aesthetics (or whose private walls have been affected) but public spaces are more a concourse of competing private interests and activities than sites for satisfying collective values of order or taste. While there is some debate about their desirability (e.g., EI Universal, 2009), street painting and messaging vary from the institutionally sponsored/artistic/moralistic to the defacing and downright insulting and are rarely considered (or controlled) as illegal in Venezuela. Thus, 'painting on walls' could have multiple connotations for adolescents. Indeed, those that have painted on walls are as likely to have done it as part of an organised school, community or political activity, as they are to have gone out at night to leave a furtive sign.

A second item in the survey asks about illegal downloading of music or films from the internet. Unauthorised and unlicensed copies of music, film, video games and software are widely available in Venezuela's informal commercial sector and rarely confiscated by the authorities (Lugo and Sampson, 2008). Despite being commonly referred to as 'pirated' (e.g., La Patilla, 2012), their existence possibly reinforces the doubts about the strict illegality of these copies and probably reflects the widespread 'neutralisation' of this offence by reference to the relatively high cost and limited accessibility of legitimate copies. With the expansion of internet and associated technologies young people are quickly socialised into a culture of downloading that carries few negative consequences. Indeed some Venezuelan respondents to ISRD-3 expressed surprise that downloading could be considered illegal.

Both of these examples reveal the normative ambiguity surrounding behaviours which, in other contexts, might be more clearly defined and recognised as illegal. They suggest that responses to these two items should be set to one side in the analysis of delinquency among Venezuelan adolescents, and that in future sweeps of the ISRD further thought needs to be given to a set of delinquency items common to all countries. 


\section{Hidden Differences}

For the heading to this section, we borrow the title of one of anthropologist Edward Hall's popular books for business (Hall and Hall, 1990). As Hall continuously emphasised, many cultural differences are not immediately apparent and are only revealed through careful study. His own approach was largely qualitative and based on extensive interviews with business leaders, leading to characterisations and classifications of key cultural features. Quantitative approaches, for example that based on the World Values Survey (e.g., Inglehart and Carballo, 1997), lead to more complicated pictures. Additionally, it is important to recognise the space for individual (e.g. Triandis et al., 1988) or group departures from the prevailing cultural 'type' found in a country. Indeed, the existence of cultural differences is ultimately a matter for careful research. Hence our exploration is speculative rather than confirmatory. We use Hofstede's ([1980]2001) concept of 'collectivist culture' as the overarching framework for examining selected characteristics of Venezuelan adolescents' social and cognitive experiences. ${ }^{5}$ In collectivist cultures, the individual is relatively tightly embedded in extended in-groups which provide support and control. By contrast, in 'individualist cultures' - found in Northern Europe and Anglo America - people are most closely wedded to their own interests and to that of their immediate family (see, also, Hui and Triandis, 1986). Collectivism and individualism have implications for social institutions such as family, community and friends, and also for cognitive frameworks that govern perceptions of time, and possibly of the self.

\section{Family}

\subsection{Which people are involved in bringing you up?} Father and mother (or stepfather/stepmother) One parent only (father or mother) Other situation (specify)

2.1 How well do you get on with your parents? I get along just fine with my father (stepfather)

\footnotetext{
${ }^{5}$ Venezuela was one of the countries included in Hofstede's sample of collectivist cultures.
} 


I get along just fine with my mother (stepmother)
I can easily get emotional care and support from my parents
I would feel very bad disappointing my parents
2.2 How many days a week do you usually eat an evening meal with your parent(s)?
2.3 How often do the following statements apply to you?
My parents know where I am when I am going out
$\ldots$
If I am out and it gets late I have to call my parents and let them know
$\ldots$
Etc.

Table 2 provides the outlines of the ISRD-3 questions about family. They focus almost entirely on the nuclear family and - in an empirical exploration of Hirschi's (1969) theory of delinquency - its functioning as an object of emotional bonding and source of social control. Question 1.6 acknowledges the possibility of alternative arrangements for bringing up children, but the subsequent questions on family refer only to parents. Two characteristics of Venezuelan housing arrangements mean that the focus on parents misses some additional important sources for attracting adolescents' affection and exerting some control over them. The first is the quite high prevalence of extended families living under the same roof, which may include one or both grandparents, parents' siblings, or more distant relations. The most recent census (2011) reports that $43.5 \%$ of Venezuelan households comprised extended families and a further $3.8 \%$ included non-family members as well (INE, 2012). Internationally, the percentage of children who are probably living with extended families is higher in Latin America (e.g., $45 \%$ in Mexico, 55\% in Colombia) than it is in Western Europe (e.g., France, 17\%) and Anglo America (e.g., United States, 29\%) (Child Trends, 2014). Additionally, the prevalence of extended families is rising in many Latin American countries, possibly because of the increasing economic challenges to establishing an independent residence (Jelin and Díaz-Muñoz, 2003). Within these extended families, responsibilities for bringing up children may be shared.

Researchers and other commentators on the Venezuelan family point to its matrifocal character, which places the mother at the centre of a network of consanguineous females who 
cooperate in many domestic tasks, including child-rearing. In its weaker form, this narrative posits a division between gender roles, with male partners taking charge of external representation, including part or all of the income generation, and sons allowed much more time outside the house than daughters. It also identifies the grandmother as a key source of authority and control over the children (De Lima and Sánchez, 2008; Hurtado, 2003). In its stronger form, the narrative speaks of male partners consigned to little more than a procreative function, under relatively transitory and unstable relationships that never imply more than a marginal role in domestic life (Moreno, 2002). In these circumstances, the female support network is even more strongly developed as, for example, mothers go out to work while grandmothers look after the children (Hurtado, 2003). This latter - 'Caribbean' (Bovenkerk and Wolf, 2010; Parrado, 2002) - family model is thought to be particularly common in low income Venezuelan households.

Income level may also be associated with a second housing arrangement, involving the clustering of related households in specific neighbourhoods. Consider, for example, the three families studied by Otálora-Montenegro and Mora-Salas (2004) living very close to each other in a low income neighbourhood of Caracas:

- Family One: male (29), female (36) - consensual union; three sons $(12,10,8)$, a fourth son is the wife's only (15).

- Family Two: female (35, sister of the male in Family One); eight daughters (ages from 2 to 19$)$, two sons $(18,5)$.

- Family Three: male (42, brother of the female in Family One, father of the six oldest children in Family 2), female (37) - married; one daughter (16), two sons $(15,10)$.

In what Otálora-Montenegro and Mora-Salas call this 'modified extended family,' the organisation of child rearing was not studied but could have involved one or a combination of intra- and interhousehold arrangements. For example, apart from receiving maternal care, some of the younger 
children in Family Two may have been significantly nurtured or supervised by their older siblings, their father from Family Three, or their uncle and aunt in Family One. Moreover, any such arrangements might have varied quite frequently over time as individual circumstances changed. This example may look exceptional because of the close physical proximity of the three households, but many family subgroups in Venezuela are co-located in the same city, if not the same neighbourhood, with the ability to establish and maintain networks of support for healthcare, childcare, meals and recreation.

The importance of family in everyone's lives is corroborated by testimony from the three Caracas households (Otálora-Montenegro and Mora-Salas, 2004:83-88) and by the results of an international comparative project on young people in twelve countries in which Venezuelan respondents were more likely than any other nationality to name the family as their primary source of help (Felce-DiPaula, 2000). These dense networks of interaction and exchange are facilitated, but not determined, by physical proximity and they underline the difficulty of treating a single household or the nuclear household as the exclusive domain for raising children and young people. As De Lima and Sánchez (2008:14) observe: '...families inhabit an enlarged space, where the house of the oldest adult, the house of each descendent, the patios, neighbouring streets and the neighbourhood are organically linked together.' This pattern of organisation, which is considered a strength rather than a weakness of the Venezuelan family (Otálora-Montenegro and Mora-Salas, 2004), particularly in the face of economic adversity, is not easily captured by static census or survey categories and requires specialised study. ${ }^{6}$ And - returning to item 2.2 of the ISRD-3 instrument - it also raises doubts about the extent to which eating an evening meal with parents is a valid indicator of family bonding in cities such as Caracas.

\section{Peers}

\section{Table 3: ISRD-3 - Leisure and Peers}

\footnotetext{
${ }^{6}$ For an experimental study in Africa of the effect of changes in household definitions on survey results, see Beaman and Dillon (2012).
} 


\subsection{Who do you spend MOST of your free time with?}

On my own

With my family

With 1-3 friends

With a larger group of friends

5.7 Some people have a friend or a group of friends they spend time with, doing things together or just hanging out. Do you have a friend or a group of friends like that?

...

5.10 Young people sometimes engage in illegal activities. How many friends do you know who have done any of the following?

I have friends who have used soft or hard drugs like weed, hash, ecstasy...

I have friends who have stolen things from a shop or department store.

...

I have friends who have beaten someone up or hurt someone badly...

Table 3 shows a sample of the items from the ISRD-3 questionnaire which ask about leisure activities and peers. As reflected in Item 5.3, the key distinction here is between family and friends, with an assumption that the only peers an adolescent will have are friends. The questions then move on to explore the level of bonding with friends and the extent to which the latter engage in delinquent behaviour. In the context of relatively large households and extended family networks these items fail to capture the contact and shared activities that take place with siblings, cousins and other family members who are close in age to the respondent. While definitely not friends, because in Venezuelan culture the distinction between family and friends is always recognised, these family members may represent a peer group that is as stable and at least as clearly identified by its affiliates as any other type of youth group. Family-related peers may spend a lot of time doing things together or 'just hanging out' and some of them may, too, have stolen from a shop or beaten someone up. Not asking about this group of peers therefore misses a potentially significant element in the lives of most Venezuelan adolescents. A recent survey of Venezuelans aged 15-29 found that $93 \%$ of respondents reported spending at least some of their free time with family and 79\% reported going out with friends (Freitez et al., 2014). The extent to which 'family' included peers, and going out with friends also included going out (time spent) with family, are unknowns. 


\section{The Last Twelve Months}

The ISRD-3 instrument probes offending by asking whether the respondent has ever engaged in a set of delinquent activities (lifetime prevalence) and, if so, how often in the last twelve months (12month incidence). Of these measures, the 12-month incidence (which can also be converted to a measure of 12-month prevalence) is the most relevant to theory testing. This is because almost all of the other items in the survey refer to the 'present' (i.e., the moment that respondents give answers). Thus, it is hoped that comparison of the 12-month prevalence of delinquency with these current measures relating to family, school, leisure and attitudes, will not lose much validity because of the lack of exact synchronicity between the corresponding reference periods.

The self-report method, of course, relies on the willingness and ability of respondents to recall and report the relevant events. When researchers have focused on recall ability, they have noted that this cannot be considered as perfect or even as invariant. The use of retrieval cues (such as a calendar) and shorter reference periods (such as six months, or one month) can increase the number of incidents recalled and help to avoid their erroneous placement ('telescoping'), whether within or outside the reference period (Junger-Tas and Haen-Marshall, 1999; Lynch and Addington, 2011). While the aspiration of developing a 'gold-standard' survey drives methodological inquiry slowly forward in industrialised research-intensive countries, international self-report surveys raise an additional consideration regarding the extent to which people in less industrialised cultures operate with a similar conception of time.

It is generally accepted that one of the distinguishing features of major cultural groups is the way in which time is conceptualised, used and talked about. For example, in a widely read book Levine (2006) proposed that people in Anglo America, Western Europe and East Asia think in terms of clock time, originally reflected and certainly reinforced by the invention of mechanical timekeeping. By 
contrast, people in Latin America and Asia think in terms of event time, which presumably divides temporal experience into irregular units defined by the beginning and end of socially significant bundles of activity such as a task (e.g., production, repair, harvesting) or a gathering (e.g., party, visit, funeral wake). As Levine (2006:137) reported it: 'Many Brazilians we tested were completely out of touch with clock time.'

A similar distinction has been proposed between collectivist cultures that are thought to operate with a 'polychronic' conception of time and individualist cultures that work with a monochronic conception (Fulmer, Crosby and Gelfland, 2014). In 'polychronic cultures' multiple and simultaneous social interactions and obligations lead to engagement in several activities at once which presumably reflect or reinforce a nonlinear conception of time. In 'monochronic cultures' time is conceived in linear terms and is built through sequences of single activities, undertaken one after another (Hall, 1983; Nonis, Teng and Ford, 2005). Western Europe and Anglo America are considered to be examples of monochronic individualist cultures, while South Asia, the Middle East and Latin America are frequently cited as examples of polychronic collectivist cultures. Finally, linguistic research has established that some languages (such as English and Indonesian) express time in linear terms while others (such as Spanish and Greek) use volume or quantity (e.g., mucho tiempo [much time]) (Casasanto et al., 2004).

Although these lines of inquiry are still at an incipient stage, they are indicative of potentially important cultural differences in conceptions of time which may have significant implications for patterns of recall. As with most self-report surveys, the ISRD-3 uses a linear conception of time, asking respondents to indicate any offending behaviours committed during the last twelve months. If Venezuelan adolescents live in a polychronic collectivist culture, their ability to place events accurately within the last twelve months may be lower than that of adolescents in the monochronic individualist 
culture of Western Europe and Anglo America. ${ }^{7}$ In the absence of systematic research, any effects of polychronic or event time on the amount and type of telescoping of delinquent behaviour can only be speculative, but cannot be dismissed. We also note that in a polychronic culture the notion of 'free time'

- one of the foci of ISRD questions - may have less resonance for respondents than it does in monochronic cultures.

\section{'Who Am I?'8}

Table 4 shows some of the items from the self-control scale used in ISRD-3, which is a shortened version of Grasmick et al.'s (1993) original tool. Respondents are asked to describe themselves by selecting an option from the Likert range that accompanies each item. The task appears straightforward and, of course, Grasmick et al.'s full or shortened scale has been validated in numerous empirical tests conducted in several countries (Tittle, Ward and Grasmick, 2003).

\section{Table 4: ISRD-3 - Self-control}

6.5 How much do you agree or disagree with the following statements?

I act on the spur of the moment without stopping to think.

I do whatever brings me pleasure here and now, even at the cost of some future goal.

I'm more concerned with what happens to me in the short run than in the long run...

Etc.

However, cultural psychologists have proposed that conceptions of the self and the sources of

information used to construct it differ between collectivist and individualist cultures. For example,

${ }^{7}$ In a study regarding recall of episodes of illness and treatment conducted in India, Das, Hammer and SánchezParamo (2012:76-77) reported that 'Illness narratives among poor households we interviewed were fractured and temporally confusing,' whereas responses from richer households 'accorded well with theoretical and cognitive models frequently used in the health economics literature.' The authors found that, compared to a week-long reference period, "Among the poor, monthly reporting "erases" almost half the morbidity burden of acute illnesses, over a third of doctor visits...and almost half of all self-medication episodes' (77). They did not explore the possible cultural dimension to the 'temporal confusion' and 'chaos' in poor people's lives, although they did note - significantly in our view - that poor households are outside the industrial organisation of markets for medical care.

${ }^{8}$ This is the repeated question in the Twenty Statements Test, used by psychologists to assess traits. In this section we briefly review current psychological thinking about the relationship between culture and personality and note some consequences for designing survey items that seek to measure the latter. 
Triandis (1989) proposed a distinction between a private self (e.g., 'I act on the spur of the moment'), a public self (e.g., 'People think that I act on the spur of the moment') and a collective self (e.g., 'My family thinks that I act on the spur of the moment'). Other things being equal, individuals in a collectivist culture may more frequently 'sample' their collective self. In a related manner, Markus and Kitayama (1991) distinguished between an independent and interdependent conception of the self. The former, thought to be prevalent in 'Western' cultures, is conceived in terms of traits and stable propensities to behave; while the latter, thought to be characteristic of Asia, Africa, Latin America, and many countries of southern Europe, is conceived in terms of interpersonal relationships and situational contingencies. While individuals in all cultures can rate themselves on traits (such as impulsivity, risk seeking), '...traits are expected to play a more important role in self-concepts, person descriptions, causal attributions, and predictions of behavior in individualistic cultures and individuals as compared to collectivistic cultures and individuals' (Church, 2000:670). If this is the case, in collectivist countries such as Venezuela trait-like measures of self-control would presumably show a weaker relationship to delinquent behaviour than behavioural measures of self-control (including behavioural measures captured through survey items). It should be noted, however, that psychologists disagree about the empirical status and significance of broad conceptual categories such as 'collectivist' and 'individualist' and much work is being conducted to explore cultural variation in conceptions of the self and their relationship to behaviour (e.g., Cheung, van der Vijver and Leong, 2011; Church, 2000; Watkins et al., 1998). As such, the implications of this research for survey design are tentative rather than definitive.

\section{Addressing Hidden Differences}

That our discussion of hidden differences is speculative rather than confirmatory reveals the incipient and provisional state of knowledge regarding variations in key dimensions of social experience and cognitive processes around the world. These represent substantial lines of future inquiry for which 
results will always be conditioned by the level of theoretical (dis)agreement, the number of sites studied, the methods used in data collection and the rate of social and individual change. To suggest that international survey projects should wait for the conclusive results from this research would therefore be to condemn them to a permanent delay. ${ }^{9}$ Meanwhile, the topics of these lines of cultural inquiry offer important suggestions regarding matters that merit sustained attention in the design and evaluation of current survey instruments. For example, future surveys of self-reported delinquency in Venezuela could develop new questions regarding household/family arrangements and peer group composition to tap into additional sources of family and peer bonding. The reference period for reporting delinquent behaviour could be shortened, and anchored in relation to a salient event (e.g., the New Year), in order to encourage accurate recall. And items measuring personal dispositions could focus on behavioural indicators instead of self-assessment of traits. The results of these innovations need to be assessed by systematic comparisons with the existing design in order to identify their impact, if any, on the process of measurement.

\section{Conclusion}

Cheung, van der Vijver and Leong (2011:595) argue that 'If one starts from an imported instrument, emic [culturally specific] aspects of a construct will remain hidden.' In our own participation in the ISRD-3 project, the need to use a standard method at all international sites led us to focus on equivalence in sampling strategy and instrument translation rather than the more comprehensive and challenging task of achieving cultural equivalence in measurement. Indeed, sampling of a school-based population with a fairly strong presence of middle income students may have led us to assume more cultural equivalence than a more detailed consideration suggests. Venezuela has been broadly

\footnotetext{
${ }^{9}$ Obviously, cross-cultural comparisons must proceed with the available data (see, for example, the article by Rocque, Posik, Haen-Marshall and Piquero in this issue). If our analysis is correct, researchers should always bear in mind the possibility that there are cultural sources of measurement error in survey data.
} 
catalogued as an Andean/Caribbean, collectivist and polychronic culture, and these labels may well capture some important characteristics, particularly among lower income groups. To the extent that they are confirmed, the inclusion of Venezuela in an international project such as the ISRD raises important questions concerning the measurement equivalence of survey instruments in different cultures. The argument is not that Venezuela is a unique case, simply that it points to the need to explore the interaction between measurement and culture both intra-nationally (e.g., in relation to migrant and minority groups) and internationally (e.g., in relation to the major cultural regions of the world).

'Hidden differences' are as much a hypothesis as a firm generalization. Their investigation demands a different approach to instrument design, involving much exploratory research to test alternative models both within and between countries. Thus, the results of any search for cultural differences that affect measurement may reveal none, few or many that are of consequence. Where significant differences exist, international instruments such as the ISRD will need to be re-designed to take account of them. This would require the involvement of multicultural teams (Greenfield, 1997) in instrument design in order to 'decenter' (Hofstede, [1980]2001) the cultural sources of content. And it would also foster more universal approaches to operationalizing key theoretical concepts - even a putatively general concept such as self-control.

\section{References}

Aebi MF (2009) Self-reported delinquency surveys in Europe. In: Zauberman R (ed) Self-Reported Crime and Deviance Studies in Europe. Brussels: VUBPRESS Brussels University Press, 11-49.

Alonso A (1998) Urban Graffiti on the City Landscape. San Diego: Western Geography Conference. URL (accessed 25 July 2014): http://www.asu.edu/courses/aph294/total-readings/alonso\%20-\%20urbangraffiti.pdf. 
Ardila A (2007) The impact of culture on neuropsychological test performance. In: Uzell B, Ponton M, and Ardila A (eds) International Handbook of Cross-Cultural Neuropsychology. London: Eurospan, 23-44.

Banville D, Desrosiers P, and Genet-Volet Y. (2000) Translating questionnaires and inventories using a cross-cultural translation technique. Journal of Teaching in Physical Education 19:374-387.

Beaman L, and Dillon A (2012) Do household definitions matter in survey design? Results from a randomized survey experiment in Mali. Journal of Development Economics 98:124-135.

Berry JW, et al. (2002) Cross-Cultural Psychology: Research and Applications. New York: Cambridge University Press.

Bovenkerk F, and Wolf T (2010) 'Surinam.' In edited by Junger-Tas J, et al. Juvenile Delinquency in Europe and Beyond: Results of the Second International Self-Report Delinquency Study. New York: Springer-Verlag, 399-407.

Casasanto DJ, et al. (2004) How deep are effects of language on thought? Time estimation in speakers of English, Indonesian, Greek, and Spanish. In Forbus K, Gentner D, and Regier T (eds) Proceedings of the 26th Annual Meeting of the Cognitive Science Society. Mahwah, NJ: Erlbaum, 186-191.

Child Trends (2014) World Family Map 2014: Mapping Family Change and Child Well-Being Outcomes.

$\begin{array}{lllll}\text { URL } & \text { (accessed } & 14 & \text { July }\end{array}$ http://worldfamilymap.org/2014/wpcontent/uploads/2014/06/WFM-2014-Final_ForWeb.pdf.

Cheung FM, van der Vijver FJR, and Leong FTL (2011) Toward a new approach to the study of personality in culture. American Psychologist 66(7):593-603.

Church AT (2000) Culture and personality: toward an integrated cultural trait psychology. Journal of Personality 68(4):651-703.

Das J, Hammer J, and Sánchez-Paramo C (2012) 'The impact of recall periods on reported morbidity and health seeking behavior.' Journal of Development Economics 98:76-88. 
De Lima B, and Sánchez Y (2008) Redes femeninas, familia popular y ancianidad en Venezuela. $\begin{array}{lllllll}\text { Perspectivas } & \text { Sociales } 10(1) . & \text { URL }\end{array}$ http://www.perspectivassociales.uanl.mx/index.php/pers/article/view/50.

Elliott DS, and Huizinga D (1989) Improving self-reported measures of delinquency. In Klein, M (ed) Cross-National Research in Self-Reported Crime and Delinquency. Dordrecht, NL: Kluwer, 155186.

El Universal (2009) ¿Cuál es tu opinión acerca de los graffitis? Caracas, October 19, 2009. URL (accessed July 18 2014): http://www.eluniversal.com/2009/10/19/dbvia_esp_cual-es-tuopinion_19A2920371.

El Universal (2011) 'Cultura del graffiti es cada vez más difícil de detener. Caracas, July 10, 2011. URL (accessed July 16 2014): http://www.eluniversal.com/2011/07/10/imp_cultura-del-graffiti-escada-vez-mas-dificil-de-detener.

Felce-DiPaula, ME (2000) Venezuela: advantaged and non-advantaged youth in Caracas. In: Gibson-Cline J (ed.) Youth and Coping in Twelve Nations: Surveys of 18-20-Year-Old Young People. New York: Routledge, 189-200.

Freitez A, et al. (2014) Encuesta Nacional de Juventud 2013. La Juventud Venezolana Protagonista de la Democracia. Caracas: Universidad Católica Andrés Bello. URL (accessed 14 July 2014): http://proyectojuventud.ucab.edu.ve/wp-content/uploads/2014/07/Resumen-para-laprensa.pdf.

Fulmer CA, Crosby B, and Gelfland MJ (2014) 'Cross-cultural perspectives on time.' In Shipp AJ, and Fried Y (eds) Time and Work, Volume 2: How Time Impacts Groups, Organizations and Methodological Choices. Hove, UK: Psychology Press, 53-75.

Grasmick H, et al. (1993) Testing the core empirical implications of Gottfredson and Hirschi's general theory of crime. Journal of Research in Crime and Delinquency 30(1):5-29. 
Greenfield PM (1997) 'You can't take it with you: why ability assessments don't cross cultures. American Psychologist 52(10):1115-1124.

Haen-Marshall, I (2010) “Pourquoi pas?” versus “Absolutely not!” Cross-national differences in access to schools and pupils for survey research. European Journal on Criminal Policy and Research 16:89109.

Hall ET (1976) Beyond Culture. New York: Doubleday.

Hall ET and Hall M (1990) Hidden Differences: Doing Business with the Japanese. New York: Doubleday. Hirschi T (1969) Causes of Delinquency. Berkeley: University of California Press. Hofstede G ([1980]2001) Culture's Consequences. Beverly Hills, CA: Sage.

Hui HH, and Triandis, HC (1986) 'Individualism-collectivism: a study of cross-cultural researchers. CrossCultural Psychology 17(2):225-248.

Hurtado S (2003) La participación discordante en la familia y los niveles de su transformación simbólica. Revista Venezolana de Economía y Ciencias Sociales 9(1):61-83.

INE (Instituto Nacional de Estadística) (2012) Procesamiento de Microdatos Censales. URL (accessed July 18 2014): http://www.redatam.ine.gob.ve/Censo2011/index.html.

Inglehart R, and Carballo M (1997) Does Latin America exist? (And is there a Confucian culture?): A global analysis of cross-cultural differences. PS: Political Science and Politics, 30(1): 34-47.

Jelin E, and Díaz-Muñoz AR (2003) Major Trends Affecting Families: South America in Perspective. New York: United Nations, Department of Economic and Social Affairs.

Junger-Tas J (2010) The significance of the International Self-Report Delinquency Study (ISRD). European Journal on Criminal Policy and Research 16:71-87.

Junger-Tas J, and Haen-Marshall I (1999) The self-report method in crime research. Crime and Justice 25:291-367. 
Junger-Tas J, Haen-Marshall I, and Ribeaud D (2003) Delinquency in an International Perspective: The International Self-Reported Delinquency Study (ISRD). Monsey, NY: Criminal Justice Press.

Junger-Tas J, et al. (eds) (2010) Juvenile Delinquency in Europe and Beyond: Results of the Second International Self-Report Delinquency Study. New York: Springer.

La Patilla (2012) Venezuela: el país donde reina la piratería. URL (accessed July 18 2014): http://www.lapatilla.com/site/2012/08/08/venezuela-el-pais-donde-reina-la-pirateria/.

Levine R (2006) A Geography of Time: The Temporal Misadventures of a Social Psychologist; or How Every Culture Keeps Time Just a Little Bit Differently. Oxford: Oneworld.

Lugo J, and Sampson T (2008) E-informality in Venezuela: the "other path" of technology. Bulletin of Latin American Research 27(1):102-118.

Lynch JP, and Addington LA (2010) Identifying and addressing response errors in self-report surveys. In Piquero AR and Weisburd D (eds) Handbook of Quantitative Criminology. New York: Springer, 251-272.

Markus HR, and Kitayama S (1991) Cultural variation in self-concept. In Strauss J and Goethals GR (eds) The Self: Interdisciplinary Perspectives. New York: Springer-Verlag, 18-48.

Messner SF and Rosenfeld R (2007) Crime and the American Dream. Belmont, CA: Wadsworth.

Nonis SA, Teng JK, and Ford CW (2005) A cross-cultural investigation of time management practices and job outcomes. International Journal of Intercultural Relations 29:409-428.

Otálora-Montenegro C, and Mora-Salas L (2004) 'La familia popular venezolana: el significado de la infidelidad en el contexto de la pobreza.' Cuadernos del CENDES 21(55):75-100.

Parrado EA (2002) Socioeconomic context, family regimes, and women's early labor market experience: the case of Colombia and Venezuela.' World Development 30(5):799-816. 
Ssamula, M (1995) Kampala (Uganda). In: Zvekic, U, Alvazzi del Frate, A (eds) Criminal Victimisation in the Developing World. Rome: United Nations Interregional Crime and Justice Research Institute, 379-410.

Thornberry T, and Krohn M (2000) 'The self-report method for measuring delinquency and crime.' In: Duffee D, et al. (eds) Criminal Justice 2000: Volume 4: Measurement and Analysis of Crime and Justice. Washington, DC: U.S. Department of Justice, 33-83.

Tittle CR, Ward DA, and Grasmick HG (2003) Self-control and crime/deviance: cognitive vs. behavioral measures. Journal of Quantitative Criminology 19(4):333-365.

Triandis HC (1989) The self and social behavior in differing cultural contexts. Psychological Review 96(3):506-520.

Triandis HC, et al. (1988) Individualism and collectivism: cross-cultural perspectives on self-ingroup relationships. Journal of Personality and Social Psychology 54(2):323-338.

Tyler TR (2006) Why People Obey the Law. New Haven, CT: Yale University Press.

Watkins D, et al. (1998) Cultural dimensions, gender, and the nature of self-concept: a fourteen-country study. International Journal of Psychology 33(1):17-31.

Wikström POH (2009) Situational Action Theory. Oxford: Oxford University Press. 